\title{
Development Status, Problems and Countermeasures of Large- and Intermediate-Scale Biogas Projects in Beijing's Mountainous Counties
}

\author{
Zhongren Zhou ${ }^{1,2}$, Zhujun Zhou ${ }^{1,3}$ \\ ${ }^{1}$ Institute of Integrated Development of Agriculture, Beijing Academy of Agriculture and Forestry Sciences, Beijing, China; ${ }^{2}$ Key \\ Laboratory of Urban Agriculture (North), Ministry of Agriculture, Beijing, China; ${ }^{3}$ College of Economics \& Management, China \\ Agricultural University, Beijing, China. \\ Email: Zhongrenzh@163.com
}

Received September 2013

\begin{abstract}
Developing large- and intermediate-scale biogas project is an important gripper of Beijing rural energy construction and "Green Beijing" construction. The existing projects have made obvious energy and environment benefits, but the overall effects have not been fully exerted. There is still a large gap between Beijing's ecological civilization goal and the operation effect. This paper takes biogas projects of Beijing seven mountainous counties as examples, the development status, ecological environment construction and existing problems of operating are explained respectively. Finally, some countermeasures and suggestions are proposed for promoting the sustainable development of biogas project in Beijing, such as strengthening technical innovation and setting standards, innovating development patterns and planning reasonable layout, improve the maintenance mechanism and intensify policy support.
\end{abstract}

Keywords: Biogas Project; Development Status; Countermeasures; Beijing

\section{Introduction}

Large- and intermediate-scale biogas project is an important type of renewable energy exploitation and utilization. It can efficiently use the agricultural waste like making the waste harmless and resourceful, producing clean energy for farmers to raise their quality of life, and reducing pollution emissions as well [1,2]. It can also change the pattern of agricultural growth, develop circular economy, and extend agriculture chain, which will improve rural surplus labor's employment and increase farmers' income. In recent years, with the supports from government policies, such as "New countryside construction”, China's large- and intermediate-scale biogas projects have made fast progress. The number of biogas project increased from 2000 in 1359, to 2009 in 72,695. The total biogas volume increased from $639,200 \mathrm{~m} 3$ to 8567,800 $\mathrm{m}^{3}$ [3]. The projects made a crucial contribution to ecological, economical and social development.

As China's capital and an oversized energy consumption city, Beijing is facing a more serious energy and environment, urban and rural issues in the construction of "Green Beijing” and the process of world city. Large and medium-sized biogas project as an effective gripper of these problems, the Beijing municipal government attach- es great importance to its development. From year 2003 to 2009, 302 million Yuan has been invested into 103 biogas engineering constructions. However, on the other hand, some technology and management problems have emerged in the course of rapid development, so that some projects cannot be used properly, even abandoned or stopped using $[2,4]$. They present a severe test of large and medium-sized biogas projects' sustainable development. This paper takes seven mountainous counties in Beijing as examples, analyzes the main factors that affect the development, and consequently provides references for regional biogas engineering's sustainable development.

\section{Current State of Biogas Projects in Beijing Mountainous Counties}

\subsection{Basic Information of Beijing Mountainous Counties}

Beijing's mountainous counties include Fangshan, Mentougou, Changping, Pinggu, Huairou, Miyun and Yanqing. Taihang Mountains is located at Beijing west and Yanshan Mountains in the north. The whole counties cover an area of $10417.2 \mathrm{~km}^{2}$, accounted for $62 \%$ of the 
Beijing area. They are important ecological barriers and water source protection areas of the capital. What's more, environment-friendly industry base is located there. They have supported the sustainable development of Beijing, meanwhile provided residents with recreational space. However, ecological environment construction as a dominant strategy limits the regional economic and social development; as a result, these regions became Beijing's economically-weak areas. According to the statistics, in 2010, per capita net income of farmers is 11,460 Yuan, accounted for $82.6 \%$ of that in flat areas, which is 13,867 Yuan.

\subsection{Large- and Intermediate-Scale Biogas Projects in Beijing Mountainous Counties}

By the end of 2010, Beijing has established 108 largeand intermediate-scale biogas projects, 64 of them are located in Beijing's seven counties, accounted for $59 \%$ of the total number. Existing biogas engineering applications of anaerobic reactor are up-flow solids reactor (USR), continuous stirred tank reactor (CSTR), high concentrations plug flow reactor (HCF), but generally dominated by USR technology. The specific distributions are: Fangshan County has 30 projects, Then Yanqing, Changping, Miyun, Pinggu and Huairou, each has 5 to 9 projects, Mentougou has only one project, but is already stopped using because of relocation. Therefore all the 64 projects' operation status are: 57 of them are operating, and the rest 7 are disused or abandoned. All of the biogas projects which supply 16,500 farmers (See Table 1).

\subsection{Ecological Environmental Effects}

There are mainly two ecological environmental benefits of large- and intermediate-scale biogas projects. First, by means of digesting the livestock waste, it is possible to produce high quality fuel instead of traditional fossil energy that can promote energy conservation and emissions reduction. Second, using biogas residue and slurry to develop circular agriculture, improve the soil, produce green organic products, and improve food safety. According to the test, if all the 64 biogas projects operated normally all the year round for $1.65 \times 10^{4}$ households, then $2.68 \times 10^{6}$ tons livestock manure would be disposed; 6.0 $\times 10^{6} \mathrm{~m}^{3}$ gases produced; $1.65 \times 10^{4}$ tce saved; $1.15 \times$ $10^{6}$ tons $\mathrm{CO}_{2}$ reduced; 8300 tons of $\mathrm{SO}_{2}$ and $\mathrm{NO}_{\mathrm{x}}$ reduced $[5,6]$. Moreover, biogas residue and slurry could be used as fertilizers, so that they can enhance crop resistance to diseases, insects, drought, and cold; increase ecological benefits. According to the analyses, the successful implementations of biogas projects have a significant effect on mountainous suburb eco-environment construction, especially reduced emission of greenhouse gases such as $\mathrm{CO}_{2}, \mathrm{SO}_{2}$ and pollution gas $\mathrm{NO}_{\mathrm{x}}$ (See Table 2).

Table 1. The operation status of biogas stations in Beijing mountainous suburb (2010).

\begin{tabular}{ccccc}
\hline \multirow{2}{*}{ County } & Total & Actual supply number (household) & \multicolumn{2}{c}{ Operation status(biogas station) } \\
\cline { 4 - 5 } & 1 & 0 & 0 & Disused or Abandoned \\
\hline Mentougou & 30 & 7036 & 28 & 2 \\
Fangshan & 7 & 1840 & 5 & 2 \\
Changping & 5 & 1383 & 5 & 0 \\
Pinggu & 5 & 1776 & 5 & 0 \\
Huairou & 7 & 3170 & 5 & 2 \\
Miyun & 9 & 1250 & 9 & 0 \\
Yanqing & 64 & 16,455 & 57 & 7 \\
Total & & & & \\
\hline
\end{tabular}

Table 2. Supply situation of biogas stations in Beijing mountainous suburb.

\begin{tabular}{|c|c|c|c|c|c|c|}
\hline County & $\begin{array}{c}\text { Number } \\
\text { (biogas station) }\end{array}$ & $\begin{array}{c}\text { Beneficiary } \\
\text { (farmer household) }\end{array}$ & Coal-saving (tce) & $\begin{array}{l}\mathrm{CO}_{2} \text { emission } \\
\text { reduction }\left(\times 10^{5} \text { tons }\right)\end{array}$ & $\begin{array}{l}\mathrm{SO}_{2} \text { emission } \\
\text { reduction (ton) }\end{array}$ & $\begin{array}{l}\mathrm{NO}_{\mathrm{x}} \text { emission } \\
\text { reduction (ton) }\end{array}$ \\
\hline Mentougou & 1 & 0 & 0 & 0 & 0 & 0 \\
\hline Fangshan & 30 & 7036 & 7036 & 4.93 & 1836.45 & 1688.47 \\
\hline Changping & 7 & 1840 & 1840 & 1.29 & 480.25 & 441.56 \\
\hline Pinggu & 5 & 1383 & 1383 & 0.97 & 360.98 & 331.89 \\
\hline Huairou & 5 & 1776 & 1776 & 1.24 & 463.55 & 426.20 \\
\hline Miyun & 7 & 3170 & 3170 & 2.22 & 827.39 & 760.72 \\
\hline Yanqing & 9 & 1250 & 1250 & 0.88 & 342.34 & 317.26 \\
\hline Total & 64 & 16,455 & 16,455 & 11.53 & 4310.96 & 3966.1 \\
\hline
\end{tabular}

Footnote: According to investigation and statistics of “Three Starting” projects, each household user saves 1 tce per year. 


\section{Main Problems}

In general, Biogas projects in Beijing mountainous suburb have made remarkable achievements. But there is still a large gap between operation status and Beijing's future ecological construction goal. The main problems are as follows:

\subsection{High Operating Cost, Poor Project Profitability}

At first, the biogas projects of Beijing mountainous counties were oriented to welfare management, so the gas charges are commonly low, about 1 to $2.1 \mathrm{Yuan} / \mathrm{m}^{3}$, equals to $1 / 3$ to $2 / 3$ the same amount of liquefied petroleum gas (LPG) expenditure. However, projects' fixed investment was higher for the first stage, and the overall running cost would be much higher if costs like raw material, management, maintenance and heating in the winter are included. With current charging standards, most of the projects cannot self-operate. Only when the government invests special funds of management and the village collective money, the projects can keep running smoothly. It means that some projects in economicallyweak areas cannot be operated normally.

\subsection{Lack of Long-Term Plan, Part of the Engineering Material Cannot Be Guaranteed}

At first, construction site must have enough raw materials of animal manure in biogas engineering. Actually, there are many other problems existing in the course of implementing, such as lacking of consideration on atmosphere and water resources protection. In the meanwhile, the adjustment of urban-rural development may limit livestock breeding, or the livestock farms are required to move. As a result, some materials of projects cannot be obtained right on the spot, running cost are increased because of external purchase.

\subsection{By-Products Are Not Efficiently Utilized, Influence Comprehensive Benefits}

One of the most important purposes of developing biogas projects is to solve organic waste pollution and produce high quality organic fertilizer. But nowadays, most of biogas residue and slurry in Beijing suburb are left unused or abandoned. For this reason, biogas manures didn't exert their values. In addition, some of them are partially aggregated or overused that exceed environment capacity, results in secondary pollution. Therefore, the biogas manures did not reflect their green economic benefits, so that the comprehensive profits of biogas projects are influenced.

\subsection{Lack of Policies Support, High Pressure on Engineering Management and Maintenance}

Since the biogas engineering serves agriculture, rural areas, and farmers, it has some public goods properties, like strong externalities. However, it only takes the form of government purchase for demonstration and promotion in earlier stage; after that, the actual operations didn't get the government subsidies, so that it brings about high pressures on engineering management and maintenance. At present, supporting policies about biogas engineering development are limited, particularly special policies. For example, in 2011, municipal government had established "Beijing Municipal Peoples Government's advice on strengthening rural infrastructure maintenance and management”, but biogas engineering management and maintenance funds of some counties are not guaranteed in place.

\section{Countermeasures and Proposals}

\subsection{Strengthening Technical Innovation, Setting Norms and Standards}

The government should strengthen technical innovation; focus on increasing unit volume gas production rate, especially low temperature fermentation problem solving. Improve operation stability, reliability, and automation level of biogas equipment. Consolidate technical support system of biogas project development of Beijing. Formulate different technology processes, routes and plans for large- and intermediate-scale biogas projects. Setting norms and standards for engineering in Beijing, standardizing stereotypes applied to related and associated equipment. Promote the standardization of engineering construction.

\subsection{Innovating Development Patterns, Planning Reasonable Layout}

Biogas engineering has minimum scale of economic operation. It's not economical if the project scale is too large for the resource capacity, because it not only leads to more resources idled and wasted, but also increases the unit cost of investment. The biogas engineering should be integrated with cycle agricultural development, produce high added-value of biogas manure, improve the overall economic performance, and strengthen the engineering's self-operation capacity. On the present basis of biogas projects, we should innovate development patterns, implement intensively scale development. The projects should supply gas to big central villages, or combined villages that adjacent. Meanwhile, on the new biogas projects layout, we should take the requirement of cities and towns development planning and ecological envi- 
ronment protection into consideration to avoid separation between the engineering and raw material bases.

\subsection{Improve the Management and Maintenance Mechanism, Intensify Policy Support}

As the saying goes, "Construction accounts for 30\%, the management accounts for 70\%". The operation performance of biogas engineering is closely related to management and maintenance. In that case, the existing institutional building should be improved and professional biogas service department be built to provide complete service assurance. The contribution of biogas projects to Beijing rural energy construction and "agriculture, rural areas, and farmers" must be recognized. During the initial stage of biogas industrialization, the government should positively carry out supportive policies, due to the high operating cost and weak market competitiveness of biogas projects, build up diversified and multichannel engineering financing system. At the same time, we should scientifically evaluate engineering's ecological and social benefits in order to carry out ecological compensation. As the support on policy-making is enhanced, policy advantages can be transformed into industrial, technical and economic advantages. Finally, the biogas projects will achieve the goal of marketization, economies of scale and low-cost.

\section{Acknowledgements}

This work was financially supported by a Innovation Fund of Beijing Academy of Agriculture and Forestry Sciences (Project no. CXJJ2013) and a research named "Study of Promoting Consulting \& Services ability (2012-2013)”

\section{REFERENCES}

[1] P. D. Zhang, X. R. Li, Y. L. Yang, et al., "Greenhouse Gas Mitigation Benefits of Large and Middle-Scale Biogas Project in China," Transactions of the CSAE, Vol. 24, No. 9, 2008, pp. 239-243.

[2] X. M. Tang, L. Chen, R. J. Dong, et al., "Survey Analysis and Advice on Large and Medium Size Biogas Plants in Beijing," Journal of Agricultural Mechanization Research, Vol. 34, No. 3, 2012, pp. 206-211.

[3] Ministry of Agriculture of the People's Republic of China, "Rural Energy Statistical Yearbook of China," Chinese Agriculture Press, Beijing, 2001-2010.

[4] Y. X. Wang, X. Su, Y. F. Tang, et al., "Status Analysis and Countermeasures of Large and Medium Scale Biogas Plants in Beijing Rural Areas,” Transactions of the CSAE, Vol. 24, No. 10, 2008, pp. 291-295.

[5] G. H. Wang, "Analysis Method on Reducing Emission of $\mathrm{SO}_{2}$ and $\mathrm{CO}_{2}$ by Rural Energy Construction," Transactions of the CSAE, Vol. 15, No. 1, 1999, pp. 169-172.

[6] H. Z. Tian, J. M. Hao, Y. Q. Lu, et al., "Evaluation of $\mathrm{SO}_{2}$ and $\mathrm{NO}_{\mathrm{x}}$ Emissions Resulted from Biomass Fuels Utilization in China,” Acta Scientiae Circumstantiae, Vol. 22, No. 2, 2002, pp. 204-208. 